\title{
MONITORING OF GREEN ROLLING METHODS AND THEIR IMPACT ON GREEN SPEED
}

\author{
Lukas Fichtl, Vadym Shapoval \\ Czech University of Life Sciences Prague \\ shapoval@tf.czu.cz
}

\begin{abstract}
This work deals with golf green rolling. Rolling slowly starts becoming an increasingly popular practice. However, it should be noted that this is one of the most unexplored parts of maintenance, not just in golf resorts. Because of greenkeepers concerns, this practice has not spread yet massively. On some issues, especially from the greenkeepers, this work tries to find answers. This report is focused on monitoring of golf green rolling methods and its impact on green speed on selected courses. In this article issues relating golf green rolling and the effects of rolling are described. The experiment compares different types of green rollers and it is focused on their impact on golf green speed increase. The aim of this experiment was to find if any type of green roller can improve green speed much more than another and if any of the experienced players would be able to recognize the difference. For all measurements the device called "Stimpmeter" was used that provides measurements of green putting speed. Another part of this research was to make economic evaluation of the investigated green rolling machines. The results of the experiment showed that the different types of used rollers have just a little effect on a final green speed increase. In other words, the differences in green speed increasing, caused by using of different green rollers, cannot be detected by any golf player. The data of the economic evaluation showed that the purchasing of the Green Tek roller is the best option from the three machines chosen for this experiment. It is mainly caused by the amount of the purchase price which was the lowest.
\end{abstract}

Keywords: golf course, green, green rolling, turf, mowing.

\section{Introduction}

Green on a golf course is the area, which takes the smallest surface on course but here goes the greater part of the game of golf. Properly shaped and proportioned green well verifies the player's ability and represents the quality of the golf course. Idealistic green should have several properties, especially stability, uniformity, surface smoothness and accuracy. The correct combination of these common signs and indicators of quality ensure the quality of the surface of putting green [1]. The qualitative indicator of the condition of the greens is the putting green speed, which can be measured by the stimpmeter.

There are a lot of different parameters and operation technics that can affect the putting green speed. Properly constructed drainage system is a very important factor, especially in areas with increased occurrence of rains. Bad constructed drainage system and frequent rain can prevent regular maintenance that can affect the putting speed[2]. Another technic that affects speed is the "double cut" technology when the second cut is usually performed perpendicularly to the first one [3]. Fertilization of greens, especially with nitrogen, can significantly impact the putting speed but it is detriment of the quality of vegetation. Reduction of the mowing height can also improve the rolling speed but it is another factor that negatively affects the quality of vegetation, especially resistance against warmness.

Another operation that can provides improving of putting green speed is rolling. Rolling is an operation that has the biggest impact to green speed increase. The using of rolling has much more significant effect on the green speed than reducing the mowing height. During the summer months it is allowed to skip moving and include rolling instead. This allows to ensure mowing of greens every second day that helps minimize the risk of stress for vegetation [4]. Rolling can also help increase the mowing height that increases defense of vegetation during summer time. As different researches show, rolling allows to increase the green putting speed without affecting compaction of the soil profile or quality of vegetation. According to few authors [5;3] the ideal amount of rolling per week is 3 times. With the right settled topdressing program and 3 times a week rolling has no negative consequences for vegetation or changes of compaction in soil. Actually, Inguagiato [6] writes that compaction is more affected by frequency of mowing than by rolling.

For research evaluation it was needed to define the value change of the putting green speed that experienced players can find out. Karcher [7] in his research states that any player is not able to recognize the difference of the putting speed change less than $160 \mathrm{~mm}$. In the study, which took place over six months the number of active golfers has been tested who had to recognize the differences 
between different speeds on individual test fields. The study was attended by players of all skill levels and ages. The results showed that none of the players was able to recognize the difference in speed less than $160 \mathrm{~mm}$. The data were also confirmed from the measurements of Nikolai [8], which state that a recognizable difference that a significant majority of players can recognize takes the values between 200 to $300 \mathrm{~mm}$. Differences in speed under $160 \mathrm{~mm}$ are not possible to recognize by any player. The main aim of this study was to define if different green rolling methods can change the putting green speed on a golf course that can be recognized by any player and calculate the economic cost for maintenance of 3 roller machines.

\section{Materials and methods}

For measuring the speed of putting green a stimpmeter was used. Before starting the measurement defining of a relatively flat area green is needed. Measuring the speed of greens consists of a measure of the distance travelled by the ball after the launch of the stimpmeter. From one place 3 balls run. The individual distances are averaged and the process is repeated in the opposite direction from this distance. When the difference in these two distances is not greater than $35 \mathrm{~cm}$, it is considered as a successful measurement. The place of the first run is labelled with white ink spray to enable measurement of an identical place in subsequent days. This procedure is based on the manual of the United States Golf Association.

The methodology of measuring the green speed depending on the rolling process consisted of comparing different ways of rolling greens. Various ways in this measurement represented the different machines, which are used for green rolling. The aim of these measurements was to find if any of used machines may cause much bigger green speed increase.

The machines used within this measurement were loaned from the ITTEC Ltd. company, which offers these machines on the Czech market. The used machines were Tru-Turf, Smithco and Green Tek. These measurements were taken at the Golf Park Podboranky and the experiment was running for two weeks. After visiting the course several putting greens were excluded because of their ruggedness, which would lead to their immeasurability. After selecting six greens, these greens were divided into 3 groups -2 putting greens for each machine. Because of the time demands and reduced crossing distances pair greens were selected. These greens are located close to each other.

By agreement with the local greenkeeper the frequency of rolling putting greens was determined. Rolling was carried out every odd day while mowing was omitted. Mowing was carried out every even day of the week. The measurement was carried out before rolling and immediately after rolling. In terms of time demands the influence of the weather could not be prevented.

Measurements were carried out on the golf course in Podboranky, located on the border of the Central and West Bohemia region near the town Jesenice. The course is built in woodland and includes 9 holes +2 training greens. The experiment was running in the period from 7.09.2015 to 17.09.2015.

Under economic evaluation a series of calculations of the fixed and variable costs were carried out. These costs were calculated for each machine. For these fixed (amortization and storage) and variable (repair and maintenance, fuel, operation and labour) cost calculations formulas 1 to 9 were used.

Amortization costs:

$$
r N_{a}=\left(C_{p}-C_{z b}\right) / t, \mathrm{CZK} \cdot \text { year }^{-1},
$$

where $C_{p}$-purcase price, CZK;

$C_{z b}$ - residual price, $\mathrm{CZK}$.

Storage costs:

$$
r N_{s}=(D+1) \cdot(S+1) \cdot r N m^{2}, \mathrm{CZK} \cdot \text { year }^{-1},
$$

where $D$-lengh, m;

$S$ - width, m;

$r \mathrm{Nm}^{2}$ - storage costs per area, $\mathrm{CZK} \cdot \mathrm{m}^{-2}$. 
Total fixed costs:

$$
r N_{f}=r N_{a}+r N_{s}, \mathrm{CZK} \cdot \text { year }^{-1} .
$$

Unitary fixed costs:

$$
j N_{f}=r N_{f} / W_{r}, \mathrm{CZK} \cdot \text { year }^{-1},
$$

where $W_{r}$-annual utilization, h.year ${ }^{-1}$.

Repair and maintenance costs:

$$
j N_{o}=\left(C_{p} \cdot k_{o}\right) /\left(t \cdot W_{r}\right), \mathrm{CZK} \cdot \mathrm{h}^{-1},
$$

where $k_{o}$-factor correction;

$t$ - timeofusage.

Fuel costs

$$
j N_{p h}=Q_{p h} \cdot C_{p h}, \mathrm{CZK} \cdot \mathrm{h}^{-1},
$$

where $Q_{p h}$ - fuel consumption, $1 \cdot \mathrm{h}^{-1}$;

$C_{p h}$-fuel price, $\mathrm{CZK} \cdot \mathrm{l}^{-1}$.

Costs of operation:

$$
j N_{m}=(m \cdot(1+0.35)) / W_{h}, \mathrm{CZK} \cdot \mathrm{h}^{-1},
$$

where $m$-labour costs, CZK $\cdot \operatorname{hod}^{-1}$;

$W_{h}$ - per hour performance, ha $\cdot \mathrm{h}^{-1}$.

Unitary variable machine costs:

$$
j N v=j N_{o}+j N_{p h}+j N_{m}, \mathrm{CZK} \cdot \mathrm{h}^{-1} .
$$

Unitary machine direct costs:

$$
j N c=j N_{f}+j N_{v}, \mathrm{CZK} \cdot \mathrm{h}^{-1} .
$$

For calculations with Green Tek vibration units were taken into account the fuel consumption of the machine, on which these units are mounted.

Statistical processing of the measured values was done in SAS 9.4. The results of this program are tables and graphs that are described in the individual measurements. For files, we tested the statistical significance of differences in mean values using the simple analysis of variance. The individual data sets have been tested to meet the condition value selection null hypothesis $H_{0}$. If the $p$-value determined by the test exceeds the value $\mathrm{p}$ of the selected level of significance $\alpha$, not rejecting the null hypothesis $H_{0}$, it means that the data are from a normal distribution and are not significantly different. Homogeneity of the variance condition is right if the $\mathrm{p}$-value for a given data set is higher than the chosen significance level $\alpha=0.05$.

\section{Results and discussion}

In the graph of Fig. 1 individual speed increasing is shown that was achieved after each green rolling. The Smithco brand model biggest speed measured increase was $0.605 \mathrm{~m}\left(1.98^{\prime}\right)$. Conversely, the lowest value was 0.22 meters $\left(0.72^{\prime}\right)$. Vibration Green Tekrolling unit increased the speed most about $0.515 \mathrm{~m}\left(1.69^{\prime}\right)$ and at least about $0.17 \mathrm{~m}\left(0.56^{\prime}\right)$. Tru-Turf roller had the biggest differences in green speed increase. The highest measured abode amounted to $0.635 \mathrm{~m}\left(2.08^{\prime}\right)$, while the lowest growth rate was $0.135 \mathrm{~m}\left(0.44^{\prime}\right)$.

In Table 1 the speed increase can be seen for every machine. For the evaluation of the measurement the median rate of these abodes was expressed. The highest green speed increase was recorded at Smithco machine and it was 0.423 meters. Smaller increase was achieved after using the Tru-Turf machine and it was 0.415 meters. The smallest green speed increase was at Green-Tek vibration units. That value was $0.355 \mathrm{~m}$.

In the graph in Fig. 2 it can be seen that the values for the machines Green-Tek, Smithco and TruTurf come from the same distribution. The median varies just at the Green-Tek vibratory roller and the maximizing variability of results were achieved at the Tru-Turf machine. 


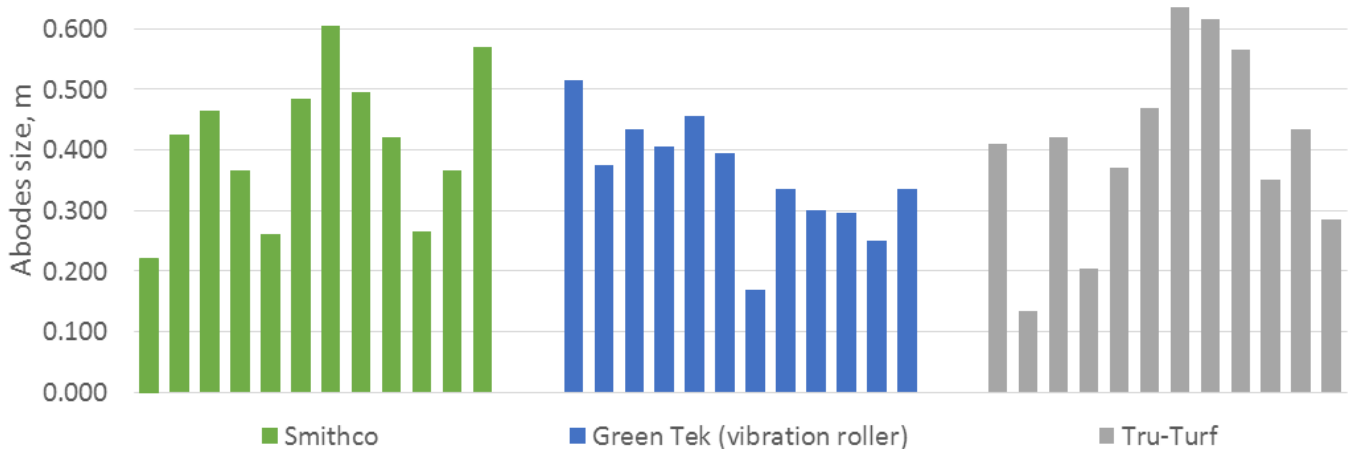

Fig. 1. Green speed increase in meters after one rolling

Speed increase of three selected mover machines

Table 1

\begin{tabular}{|c|c|c|c|c|}
\hline $\begin{array}{c}\text { Date of } \\
\text { measurement }\end{array}$ & $\begin{array}{c}\text { No. of } \\
\text { green }\end{array}$ & Smithco & Green Tek & Tru-Turf \\
\hline \multirow{2}{*}{ 7.9.2015 } & 1. & 0.220 & 0.515 & 0.410 \\
\cline { 2 - 5 } & 2. & 0.425 & 0.375 & 0.135 \\
\hline \multirow{2}{*}{ 9.9.2015 } & 1. & 0.465 & 0.435 & 0.420 \\
\cline { 2 - 5 } & 2. & 0.365 & 0.405 & 0.205 \\
\hline \multirow{2}{*}{ 11.9.2015 } & 1. & 0.260 & 0.455 & 0.370 \\
\cline { 2 - 5 } & 2. & 0.485 & 0.395 & 0.470 \\
\hline \multirow{2}{*}{ 13.9.2015 } & 1. & 0.605 & 0.170 & 0.635 \\
\cline { 2 - 5 } & 2. & 0.495 & 0.335 & 0.615 \\
\hline \multirow{2}{*}{ 15.9.2015 } & 1. & 0.420 & 0.300 & 0.565 \\
\cline { 2 - 5 } 17.9.2015 & 2. & 0.265 & 0.295 & 0.350 \\
\cline { 2 - 5 } & 1. & 0.365 & 0.250 & 0.435 \\
\hline Median & 2. & 0.570 & 0.335 & 0.285 \\
\hline
\end{tabular}

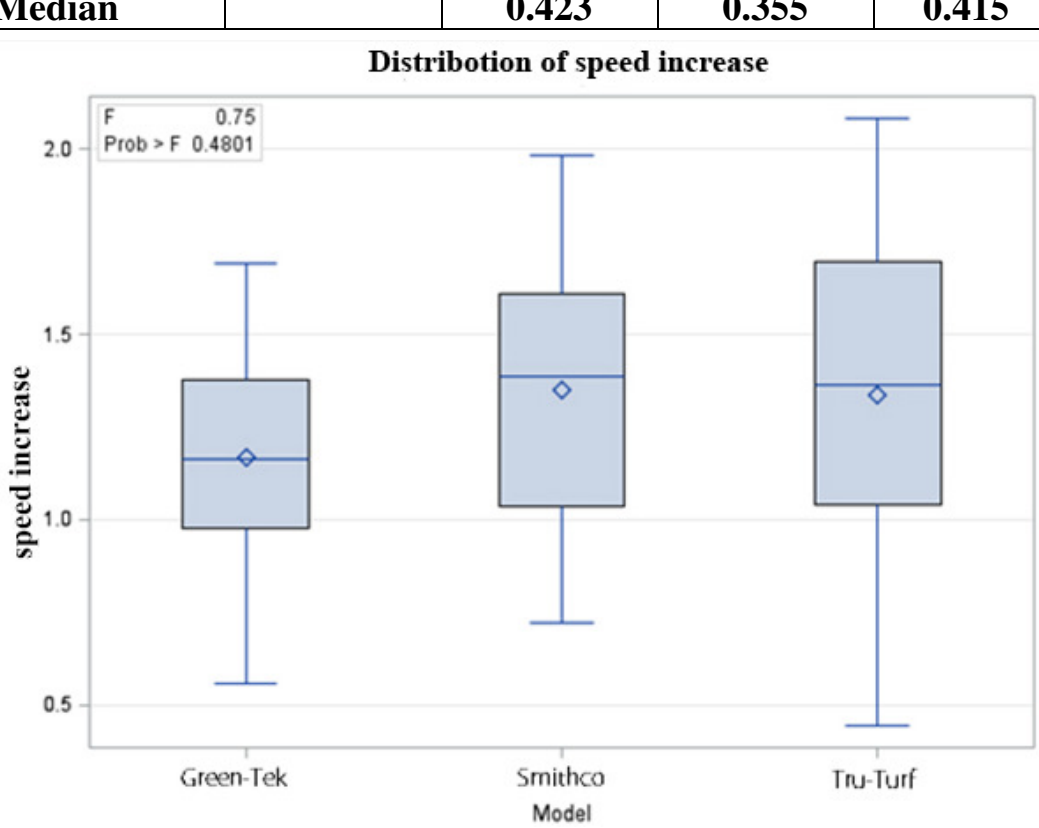

Fig. 2. Speed increase box graph

Using the Levene's test the assumption of conformity variance the p-value was calculated that is 0.1988 (Table 2). This value is higher than the selected level of significance $\alpha$ and therefore does not reject the hypothesis $H_{0}$. The assumptions that values are significantly different to each other are met. In case if the hypothesis $H_{0}$ is rejected, it would be necessary to carry out detailed variance classification. To verify that the data from the Levene's test are right a test known as the Tuckey test 
was conducted. This test showed that the data are not statistically different from each other and the values are ranked in one group.

Table 2

\section{Levene's test results}

\begin{tabular}{|c|c|c|c|c|c|}
\hline \multicolumn{6}{|c|}{$\begin{array}{c}\text { Levene's Test for Homogeneity of pr_rychlosti Variance } \\
\text { ANOVA of Squared Deviations from Group Means }\end{array}$} \\
\cline { 1 - 5 } Source & DF & $\begin{array}{c}\text { Sum of } \\
\text { Squares }\end{array}$ & Mean Square & $\boldsymbol{f}$ & $\operatorname{Pr}>\boldsymbol{F}$ \\
\hline Model & 2 & 0.00108 & 0.000542 & 1.70 & 0.1988 \\
\hline Error & 33 & 0.0105 & 0.000319 & \\
\hline \multicolumn{7}{|c|}{$\begin{array}{c}0.05 \\
0.1988\end{array}$} & 0.05 & $\rightarrow$ & Not different
\end{tabular}

For calculation of the fixed and variable costs individual data of the machines were used that were provided by the employees of ITTEC Ltd. Data of annual machine utilization are based on the maximum assumed utilization of the machine according to the period of the year when the golf course is maintained. Maintenance time of the golf course was set for April until the end of October. In this period green rolling can be used up to 3 times a week and it was calculated that performance of work operations on a eighteen-hole course will take in average up to 3 hours. Further, the calculation is performed with a low coefficient of repairs, because it is envisaged that the machines are new. For vibration units of Green Tek to the machine consumption on which these units are mounted is considered. For the calculations formulas listed in the methodology of economic evaluation were used. The results of calculations are shown in Table 3 for each machine separately.

Table 3

Economic evaluation of fixed and variable costs

\begin{tabular}{|l|c|c|c|c|}
\hline Fixed costs & Units & Smithco & Green Tek & Tru-Turf \\
\hline Amortization costs $-r N a$ & $\mathrm{CZK} \cdot \mathrm{year}^{-1}$ & 34500.00 & 27000.00 & 29000.00 \\
\hline Storage costs $-r N s$ & $\mathrm{CZK} \cdot \mathrm{year}^{-1}$ & 609.84 & 475.20 & 552.00 \\
\hline Total fixed costs $-r N f$ & $\mathrm{CZK} \cdot \mathrm{year}^{-1}$ & 35109.84 & 27475.20 & 29552.00 \\
\hline Unitary fixed costs $-j N f$ & $\mathrm{CZK} \cdot \mathrm{year}^{-1}$ & 125.84 & 98.48 & 105.92 \\
\hline Variable costs & Units & Smithco & Green Tek & Tru-Turf \\
\hline Maintenance costs $-j N o$ & $\mathrm{CZK} \cdot \mathrm{h}^{-1}$ & 46.37 & 36.29 & 38.98 \\
\hline Fuel costs $-j N p h$ & $\mathrm{CZK} \cdot \mathrm{h}^{-1}$ & 155.00 & 90.00 & 155.00 \\
\hline Costs of operation $-j N m$ & $\mathrm{CZK} \cdot \mathrm{h}^{-1}$ & 162.00 & 162.00 & 162.00 \\
\hline Unitary variable costs $-j N v$ & $\mathrm{CZK} \cdot \mathrm{h}^{-1}$ & 363.37 & 288.29 & 355.98 \\
\hline Unitary machine direct costs- $j N c$ & $\mathrm{CZK} \cdot \mathrm{h}^{-1}$ & 489.21 & 386.77 & 461.90 \\
\hline
\end{tabular}

Unitary machine direct costs of the machines Smithco and Tru-Turf are not much different, but there is a difference in the amount of the purchase price, which is the highest at the Smithco roller. The results showed that the lowest unitary costs are achieved with the Green Tek vibratory roller. A significant difference of the unitary costs between the Green Tek roller and the other machinery is mainly caused by the amount of the purchase price, which is the lowest of all at the Green Tek roller. At the end, the fuel consumption has significant value too and again this result is the lowest with the Green Tek roller. The highest speed increase was recorded with the SMITHCO roller $(0.423$ meters $)$, then the next machine Tru-Turf $(0.415 \mathrm{~m})$ and the lowest speed increase was with Green Tek $(0.355$ meters). It should be noted that all machines increased speed more than one foot (more than $0.3048 \mathrm{~m}$ ).

The difference between the highest and lowest increase caused by different machines is $68 \mathrm{~mm}$. It is proved that any player cannot detect any differences in the green speed less than $160 \mathrm{~mm}$. So, it is not much important, which green rolling machine is used. This statement is supported by statistical evaluation of the measurement. This showed that the speed increase caused by different machines has not a statistically significant difference. The differences that are between individual machines, especially the weight and construction, do not result almost in any effect. 
The results show that rolling can increase the green speed and prove the knowledge from the literature review that, if the frequency is set up to 3 times in a week, there are no detectable changes of vegetation or soil compaction. When including rolling instead of classic mowing, it may occur in reducing the total cost of upkeep of the machinery for green mowing. The big cost item for these mowers remains frequent sharpening. Costs can be reduced up to half in cases when the frequency of mowing is reduced instead of rolling. From the foregoing, it records that rolling has almost no drawbacks and can be only recommended.

\section{Conclusions}

The results show that machines for green rolling do not have a significant effect on the final green putting speed. It is obvious that the different machines will cause various values. These differences that were achieved between each machine are so small that no players are able to recognize these differences. The differences between speeds caused by different machines were statistically evaluated and there is no a significant statistical difference between them.

However, the assertion remains valid that rolling can provide reduction of overall costs for green maintenance, help maintain better quality of vegetation and reduce soil compaction. In this study the economic evaluation of the cost of rolling the machines has been carried out. The results show that the Green Tek rolling unit has the least costs to operate the machine. So, it means that is more important to choose a machine with lower overall costs that can provide the same quality of the rolling operation as an expensive one.

\section{Acknowledgements}

This work was supported by Czech University of Life Sciences internal project IGA "Evaluation of Accuracy of Determing Position by RTK Recievers".

\section{References}

1. Beard J. B. Turf management for golf courses. 2nd ed. Chelsea, MI: Ann Arbor Press, 2002. 793 p. ISBN 1575040921.

2. Sweeney P., Hamilton G., Dannerberger K. Factors Affecting Green Speed. Ohio State University and Pennsylvania State University,2000. 8 p. [online][2016.03.07]. Available at:

http://plantscience.psu.edu/research/centers/turf/extension/factsheets/factors-affecting-greenspeed/extension_publication_file

3. Nikolai T. The superintendent's guide to controlling putting green speed. Hoboken N.J.: John Wiley \& Sons, 2005.160 p. ISBN 0471472727.

4. Strunk W. D. Mowing and Light-weight Rolling of Creeping Bentgrass (Agrostisstolonifera L.). Putting Greens during summer heat stress periods in the Transition Zone. Knoxville,Master's Thesis, University of Tennessee, 2006. 77 p. [online][ 2016.03.07]. Available at: $\mathrm{http} / / /$ trace.tennessee.edu/cgi/viewcontent.cgi?article=3162\&context=utk_gradthes

5. Giordano P. L., Vargas J. M., Nikolai T. A.,Hammerschmidt R.Why lightweight rolling decreases dollar spot.In: Golf Course Management, 2012, February, pp. 138-142. [online][2016.03.12].Available at: http://turf.umn.edu/sites/g/files/pua2626/f/media/rolling-anddollar-spot.pdf

6. Inguagiato J. C., Murphy J.A., Clarke B.B. Mowing and rolling strategiesto manage anthracnose on annual bluegrass greens.In: Golf Course Management, 2009, May, pp. 111-116. [online] [2016.03.11]. Available at:

http://www.gcsaa.org/uploadedfiles/course/pests-and-diseases/diseases/anthracnose/mowing-androlling-strategies-to-manage-anthracnose-on-annual-bluegrass-greens.pdf

7. Karcher D., Nikolai T., Calhoun R. Golfers' perceptions of greens speedsvary. In:Golf Course Management,2001,March, pp. 57-60. [online][2016.03.22]. Available at:

http://puttingzone.com/Info/Bag/2. \%20Golfers' \%20perceptions \%20of \%20green \%20speed \%2 0vary.pdf.

8. Nikolai T. A. More Light on Lightweight Rolling. In:Green Section Record,2002. Jan-Febr, pp. 9-12. [online][2016.03.11]. Available at:

http://gsrpdf.lib.msu.edu/ticpdf.py?file=/2000s/2002/020109.pdf 